\title{
Mouse Thymic Lymphoma
}

National Cancer Institute

\section{Source}

National Cancer Institute. Mouse Thymic Lymphoma. NCI Thesaurus. Code C134997.

A lymphoma that arises in the thymus of a mouse. 